\title{
IL-6 Contributes to Corneal Nerve Degeneration after Herpes Simplex Virus Type I Infection
}

\author{
Ana J. Chucair-Elliott, ${ }^{*}$ Jeremy Jinkins, ${ }^{*}$ Meghan M. Carr, ${ }^{*}$ and Daniel J.J. Carr* ${ }^{* \dagger}$
}

From the Departments of Ophthalmology* and Microbiology and Immunology, ${ }^{\dagger}$ University of Oklahoma Health Sciences Center, Oklahoma City, Oklahoma

\author{
Accepted for publication \\ June 9, 2016 \\ Address correspondence to \\ Ana J. Chucair-Elliott, Ph.D., \\ Department of Ophthalmology, \\ University of Oklahoma \\ Health Sciences Center, 608 \\ Stanton L Young Blvd, Okla- \\ homa City, OK 73104. E-mail: \\ ana-chucair@ouhsc.edu.
}

\begin{abstract}
Herpes simplex virus type 1 (HSV-1) is a leading cause of neurotrophic keratitis characterized by decreased corneal sensation because of damage to the corneal sensory fibers. We and others have reported regression of corneal nerves during acute HSV-1 infection. To determine whether denervation is caused directly by the virus or indirectly by the elicited immune response, mice were infected with HSV-1 and topically treated with dexamethasone (DEX) or control eye drops. Corneal sensitivity was measured using a Cochet-Bonnet esthesiometer and nerve network structure via immunohistochemistry. Corneas were assessed for viral content by plaque assay, leukocyte influx by flow cytometry, and content of chemokines and inflammatory cytokines by suspension array. DEX significantly preserved corneal nerve structure and sensitivity on infection. DEX reduced myeloid and T-cell populations in the cornea and did not affect viral contents at 4 and 8 days post infection. The elevated protein contents of chemokines and inflammatory cytokines on infection were greatly suppressed by DEX. Subconjunctival delivery of neutralizing antibody against IL- 6 to infected mice resulted in partial preservation of corneal nerve structure and sensitivity. Our study supports a role for the immune response, but not local virus replication in the development of HSV-1-induced neurotrophic keratitis. IL- 6 is one of the factors produced by the elicited inflammatory response to HSV-1 infection contributing to nerve regression. (Am J Pathol 2016, 186: 2665-2678; http://dx.doi.org/10.1016/j.ajpath.2016.06.007)
\end{abstract}

Nerves from the peripheral nervous system can be damaged during trauma or disease. Specifically, the cornea, which receives the densest innervation of the body, can be severely affected by the development of peripheral neuropathies. ${ }^{1}$ Corneal fibers, mainly sensory in origin and derived from the trigeminal nerve, form the afferent arm of reflexes for blinking and tearing. This function is accomplished by sensing thermal, mechanical, and chemical stimuli and by releasing factors that are crucial to the maintenance and homeostasis of the ocular surface. ${ }^{1,2}$ For these reasons, innervation anomalies affect cell metabolism, proliferation, and wound healing that compromise the healthy state of the cornea and visual axis. Neurotrophic keratitis (NTK) is a degenerative disease caused by impairment of the trigeminal corneal innervation, leading to corneal epithelial breakdown, impairment of healing, and development of ulceration, melting, and perforation. ${ }^{3}$ The hallmark of NTK is decreased or absent corneal sensation, common to all stages of its diagnosis. ${ }^{3,4}$ Examples of noninfectious causes of NTK include trigeminal nerve damage associated with orbital and head injury, head trauma, aneurysms, or intracranial neurological disease, laser in situ keratomieulieusis procedures, and diabetes mellitus. ${ }^{5-8}$ Herpetic viral infections of the cornea, such as herpes simplex virus type 1 (HSV-1), are thought to be a major cause for the development of NTK. ${ }^{5,9,10}$ Shortly after replicating at the initial site of infection, HSV-1 uses retrograde axonal transport to gain access to the sensory neurons in the trigeminal ganglia, where it establishes latency. ${ }^{11}$ Repeated cycles of reactivation can lead to herpes stromal keratitis, an extensively studied immunopathological process. ${ }^{12-16}$ Herpes stromal keratitis is characterized by scarring, opacities, and neovascularization of the cornea, ${ }^{13,17-19}$ and is associated with impairment of corneal nerve sensation. ${ }^{20-22}$ Addressing the mechanism(s) leading to the development of viral-induced NTK has clinical

Supported by NIH grant R01 EY021238 (D.J.J.C.), National Eye Institute core P30 EY021725, Oklahoma Center for Adult Stem Cell Research grant through the Oklahoma Tobacco Settlement Endowment Trust (D.J.J.C.), and Research to Prevent Blindness unrestricted grant.

Disclosures: None declared. 
relevance because the identification of target cells and factors has the potential of advancing our understanding of a broad spectrum of peripheral neuropathies that develop in disease settings with inflammation (eg, diabetes mellitus, bacterial infection, and chemical burns). We previously reported that HSV-1 infection of the mouse cornea causes nerve regression during the acute phase of infection, followed by an abnormal process of regeneration. ${ }^{23}$ Although $\mathrm{CD} 4^{+} \mathrm{T}$ cells, a set of inflammatory cells infiltrating the cornea, have been suggested to influence the long-term persistence of corneal nerve defects after HSV-1 infection, ${ }^{22}$ whether the initial events of nerve regression after infection are elicited by inflammatory cells/ mediators, or by other means, such as viral infection of the cornea, resident cell response, or signaling within the trigeminal ganglia, remains a debatable question. To test the hypothesis that the elicited immune response to HSV-1 infection is responsible for the regression of corneal nerves during acute infection, we analyzed the effect of the antiinflammatory drug dexamethasone sodium phosphate $(\mathrm{DEX})^{24-26}$ in the corneal nerve network structure and function, and uncovered potential cells and factors as part of the mechanism of HSV-1-induced NTK.

\section{Materials and Methods}

\section{Animals}

All animal procedures were approved by the University of Oklahoma Health Sciences Center and Dean McGee Eye Institute Institutional Animal and Care and Use Committee and performed in adherence to the Association for Research in Vision and Ophthalmology Statement for the Use of Animals in Ophthalmic and Vision research. C57BL/6 mice were obtained from The Jackson Laboratory (Bar Harbor, ME). Mice were 6 to 8 weeks old at the time of performing experiments. Before tissue harvesting, mice were deeply anesthetized with ketamine/xylazine and euthanized by cardiac perfusion with phosphate-buffered saline.

\section{Virus and in Vivo Infection}

Anesthetized mice were infected by scarification of the corneal surface, followed by the application of $3.0 \mu \mathrm{L}$ of phosphate-buffered saline containing HSV-1 strain McKrae $\left(10^{3}\right.$ plaque-forming units per eye). ${ }^{27}$ Controls were performed as previously described.

\section{DEX Treatment}

Starting at 2 hours post infection (pi) or at 2 days pi, nonanesthetized mice were held by the scruff of the neck, and topically delivered a drop of $0.1 \%$ DEX ophthalmic solution (Bausch + Lomb Inc., Tampa, FL; \#001-000050-00) onto their corneas $(20 \mu \mathrm{L})$. Control treatments (VEH) were performed by applying lubricant eye drops (Allergan, Inc., Irvine, CA) onto each cornea. The treatments were applied four times a day between $7 \mathrm{Am}$ and $7 \mathrm{PM}$, for up to 8 days pi. For i.p. delivery, DEX (West-Ward Pharmaceuticals, Eatontown, NJ; \#0641-0367-25) was diluted with phosphate-buffered saline to inject a dose of $10 \mathrm{mg} / \mathrm{kg}(100 \mu \mathrm{L})$, immediately after the cornea infection procedure and at 4 days pi.

\section{Corneal Sensitivity}

A Cochet and Bonnet esthesiometer (Luneau SAS, Prunayle-Gillon, France; 8630-1490-29) was used to test for corneal sensitivity. Briefly, nonanesthetized mice were presented a monofilament at different lengths $(6.0$ to $0.5 \mathrm{~cm})$ to elicit a blink response. ${ }^{23}$

\section{Slit-Lamp Examination of the Corneas}

A Micron III imaging platform with a slit-lamp attachment (Phoenix Research Laboratories, Pleasanton, CA) was used for anterior segment imaging of anesthetized mice. ${ }^{28}$

\section{Neutralization of IL-6}

At 1 hour pi, deeply anesthetized mice were subconjunctivally administered $5 \mu \mathrm{g}$ of anti-IL-6 antibody or isotype control antibody (normal goat $\mathrm{IgG}$ ) to both eyes (R\&D Systems, Minneapolis, MN; AB-406-NA and AB$108-\mathrm{C}$, respectively; volume of injection $=10 \mu \mathrm{L}$ ) using a 31-gauge syringe under a dissecting scope. The injections were repeated every 2 days and mice were kept in the vivarium until the corneas were collected at 8 days pi.

\section{Immunochemistry and Imaging}

For immunostaining of cornea flat mounts, eyes were removed and an incision was made posterior to the limbus to dissect the corneas, including a margin of sclera. The corneas were fixed, permeated, and incubated overnight sequentially with blocking, primary antibody, and secondary antibody solutions, as previously described. ${ }^{23}$ The primary antibodies included were anti- $\beta$ III tubulin (Abcam, Cambridge, MA; 18207, 1:1000) ( $\beta$ III tubulin) and anti-CD31 (EMD Millipore, Billerica, MA; MAB1398Z, 1:100). Incisions were made in each cornea to obtain a flower-shaped whole mount (four quadrants) before mounting in 50\% glycerol. Imaging of cornea samples was performed on an Olympus FluoView confocal laser scanning microscope (FV500 v5.0 or FV1200, FV10-ASW 4.2; Olympus, Center Valley, PA). Microscope and software settings were identical for all samples within experiments. The size of the Z-stack generated for cornea flat mounts was 10 to 12 slices thick $(4.77-\mu \mathrm{m}$ step size $)$ at $\times 10$ magnification. To quantify changes in corneal innervation and vasculature, the MetaMorph offline software version 7.7.0.0 (Molecular Devices, LLC, Sunnyvale, CA) was used to calculate the percentage threshold area positive for $\beta$ III tubulin or CD31 staining on acquired confocal images. This threshold area is defined as the percentage of $\beta$ III tubulin ${ }^{+}$or 
$\mathrm{CD} 31^{+}$pixels divided by the total number of pixels in the entire image. For each cornea, a representative image from each quadrant was used for analysis (four images per sample where the visual field included the peripheral limbus toward the center of the cornea proper). ${ }^{23}$ For indicated representative images that underwent quantitative analysis, a Z-stack containing fewer optical sections (three slices, 4.77- $\mu \mathrm{m}$ step size) was performed to display the subbasal corneal network (subepithelial) without the thick stromal fibers (FV 10-ASW $4.0 \mathrm{v}$; Olympus). For immunostaining of sagittal frozen sections, fixed cornea samples were cryoprotected by overnight incubation with $30 \%$ sucrose and then frozen in optimal cutting temperature media. Corneal cryostat sections $(14 \mu \mathrm{m}$ thick) were permeated, blocked, and immunostained with anti-B III tubulin and anti-substance P (BD Pharmingen, San Jose, CA; 556312, 1:200) antibodies. ${ }^{23}$ Confocal imaging of representative areas was performed to generate a Z-stack of five slices $(4.77-\mu \mathrm{m}$ step size $)$ at $\times 20$ magnification.

\section{Viral Plaque Assay}

Corneas were homogenized with a tissue miser, clarified by centrifugation, and then serially diluted onto a confluent lawn of Vero cells in media containing 10\% fetal bovine serum and antibiotic/antimycotic reagents. Plaques were visualized and enumerated with the aid of an inverted microscope 24 to 48 hours later and quantified as mean log plaque-forming units per pair of corneas or per cornea, as previously described. ${ }^{27}$

\section{Flow Cytometry}

Corneas were harvested and digested in 1.0 to $2.0 \mathrm{mg} / \mathrm{mL}$ type 1 collagenase in normal media at $37^{\circ} \mathrm{C}$ with mechanical dissociation (a pair of corneas/sample). The resulting cell suspension was filtered and labeled for flow cytometric analysis of myeloid and T-cell populations. Samples were analyzed using a MacsQuant flow cytometer and MacsQuantify software version 2.6 (Miltenyi Biotec, Bergish Gladbach, Germany), as previously described. ${ }^{29}$ Briefly, the phenotype of myeloid populations was based on a gating strategy that selects cells in the scatter range that are CD45 ${ }^{+}$ and subsequently $\mathrm{F} 4 / 80^{+} \mathrm{GR} 1^{-}$(macrophages), F4/ $80^{+} \mathrm{GR} 1^{+}$(inflammatory monocytes), and $\mathrm{F} 4 / 80^{-} \mathrm{GR} 1^{+}$ neutrophils [polymorphonuclear cells (PMNs)]. After using scatter properties to select lymphocytes, positive selection for $\mathrm{CD} 45^{+}$cells, and subsequent positive selection for $\mathrm{CD}^{+}$ cells, all $\mathrm{T}$ cells were then analyzed for $\mathrm{CD} 4\left(\mathrm{CD} 4^{+} \mathrm{T}\right.$ cells) and $\mathrm{CD} 8\left(\mathrm{CD}^{+} \mathrm{T}\right)$ expression. The antibodies included were as follows: anti-mouse CD45: eFluor450 (clone 30-F11), anti-mouse Gr1: phycoerythrin (clone RB6-8C5), anti-mouse CD3e: fluorescein isothiocyanate (145-2C11), anti-mouse CD4: allophycocyanin (clone GK1.5), anti-mouse CD8a: phycoerythrin (clone 53-6.7) (eBioscience, San Diego, CA), and anti-mouse F4/80: allophycocyanin (clone $\mathrm{Cl}$ :A3-1) (Bio-Rad Laboratories, Hercules, CA).

\section{Protein Extraction, Suspension Array, and Western Blot}

Corneas were harvested and homogenized in T-PER tissue protein extraction reagent (Thermo Scientific, Pittsburgh, PA; 78510) supplemented with $1 \times$ protease inhibitor cocktail (EMD Millipore; 539131) using a tissue miser. The supernatants from tissue homogenates were assayed for protein content using a BCA protein method (Thermo Scientific; 23225). For suspension array, analyte concentrations of interest were determined using a Bio-Rad Bioplex system (Bio-Rad Laboratories). Milliplex Map Luminex-based assays (EMD Millipore; MCYTOMAG-70K) were used to quantify c-x-c motif chemokine ligand (CXCL)-2, CXCL-9, and CXCL-10, c-c motif chemokine ligand (CCL) 2, CCL3, and CCL5, and inflammatory cytokines: IL- $1 \alpha$, IL-1 $\beta$, IL-2, IL-4, IL-12 (p40), IL-17, tumor necrosis factor- $\alpha$, and interferon (IFN)- $\gamma$. The content of each detected analyte was normalized to the protein content in the sample and results were expressed as pg analyte/mg protein. Western blot technique and analysis were performed as previously described. ${ }^{23}$ Anti-herpes virus entry mediator and antinectin-1 were purchased from Santa Cruz Biotechnology, Inc. (Dallas, TX; sc-365971 and sc-28639, respectively, diluted at 1:1000). Anti- $\beta$-actin, loading control, was purchased from Abcam (ab23578, diluted at 1:10,000). The net intensity for each protein band was normalized to $\beta$-actin, and data were expressed as normalized net intensity.

\section{Real-Time Quantitative RT-PCR}

Total RNA from two corneas was extracted with TRIzol reagent (Ambion, Life Sciences, Grand Island, NY) converted to cDNA (iScript reverse transcription supermix; Bio-Rad Laboratories), as previously described. ${ }^{23}$ The transcript levels of nerve growth factor (NGF), neurotrophin (NTF)3, NTF5, brain-derived neurotrophic factor, glial cell line-derived neurotrophic factor (GDNF), ciliary neurotrophic factor, leukemia inhibitory factor, and hypoxanthine guanine phosphoribosyl transferase (housekeeping gene) were measured using customized PrimePCR plates following the manufacturer's guidelines (Bio-Rad Laboratories; 100-25217). Primer unique IDs following the above mentioned order are: qMmuCID0040099, qMmuCED00 39922, qMmuCED0003775, qMmuCED0004519, qMmuCID0023525, qMmuCED0039774, qMmuCED0001055, qMmuCID0005641, qMmuCID0005613, and qMmuCED0 045738. Relative quantities of gene expression were calculated by the comparative $\mathrm{C}_{\mathrm{T}}$ value method, and the results were expressed as fold-change of expression for each transcript. ${ }^{23}$

\section{Statistical Analysis}

Statistical analysis was performed by using GraphPad Prism software version 5.0 (GraphPad Software, San Diego, CA). ${ }^{23,30}$ The data are expressed as the means \pm SEM for 

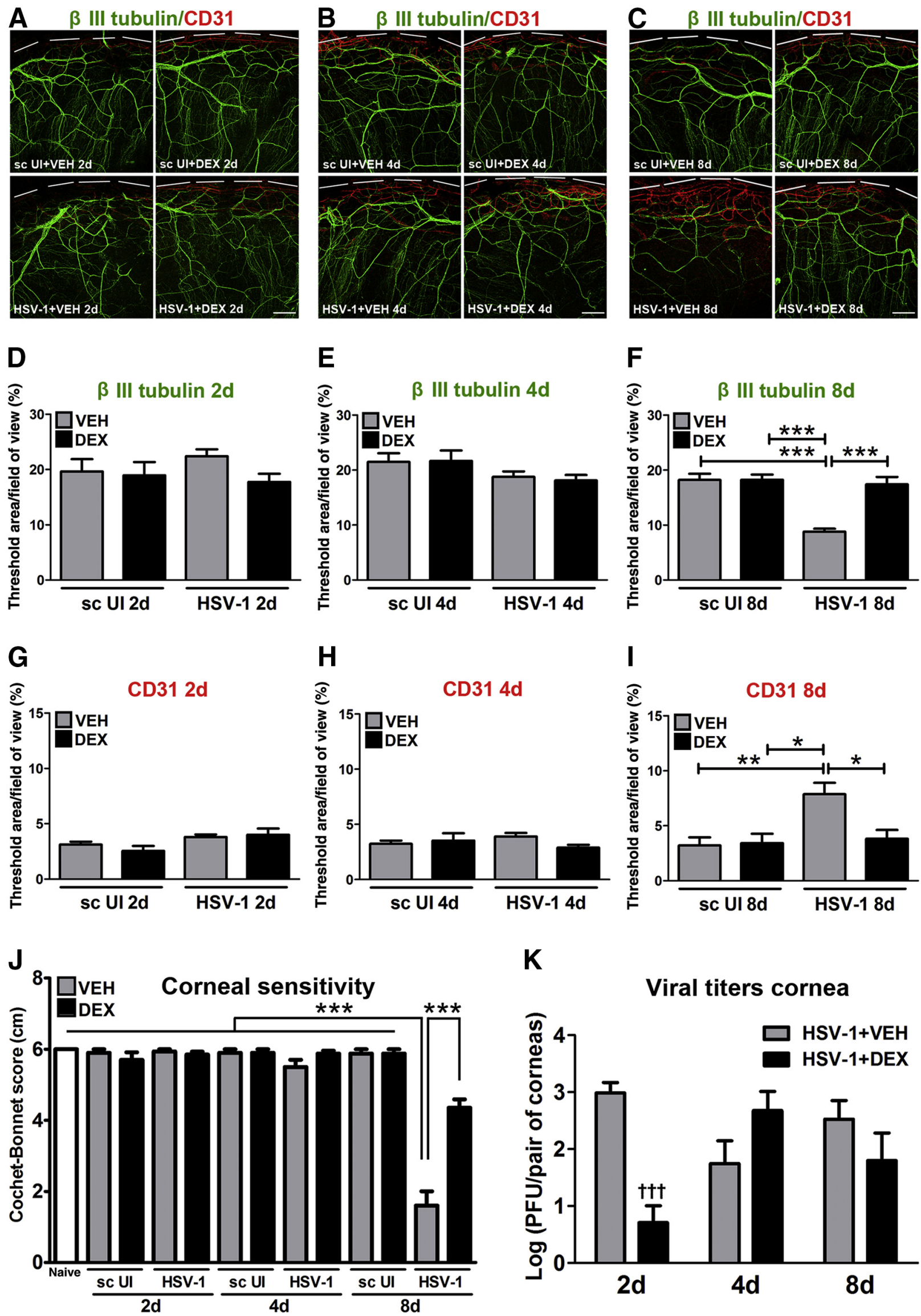

K

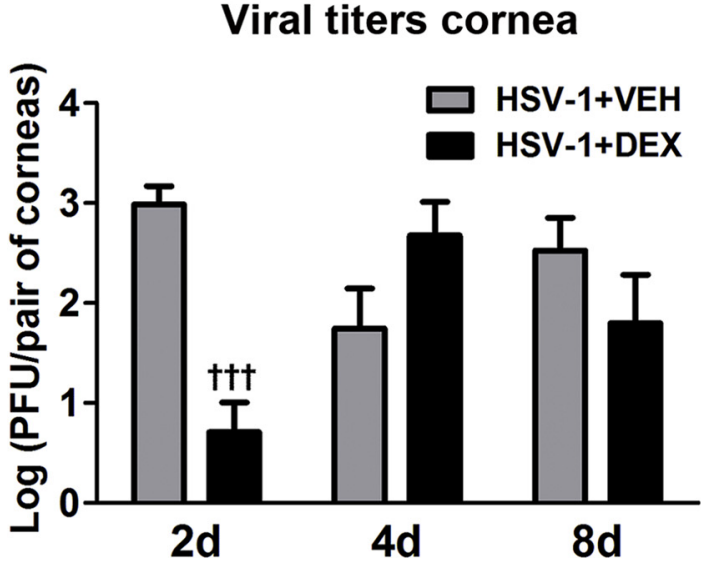


each group. The unpaired $t$-test was performed to assess the significant differences $(P<0.05)$ between two groups. For multiple comparisons, one-way analysis of variance was performed, followed by the Bonferroni post hoc test.

\section{Results}

\section{DEX Prevents Corneal Nerve Regression and Sensation Loss after HSV-1 Infection}

After HSV-1 infection of the cornea, resident cells, including infected epithelial cells, release chemokines that recruit PMNs, macrophages, inflammatory monocytes, and natural killer cells, followed by a second wave of cells composed primarily of $\mathrm{CD}^{+}$and $\mathrm{CD}^{+}{ }^{+}$cells. ${ }^{13,31}$ Previously, we reported that HSV-1 causes regression of sensory fibers innervating the cornea and loss of their function during the acute phase of infection, followed by abnormal nerve regeneration at a time point consistent with establishment of viral latency. ${ }^{23}$ Since 8 days pi, the time point pi of maximal observed loss of innervation, coincides with a highly inflammatory milieu in the infected cornea, ${ }^{12,14}$ we hypothesized the mechanism triggering regression of corneal nerves is immune system mediated. To test this hypothesis, we evaluated the effects of DEX, a clinically prescribed, anti-inflammatory reagent, ${ }^{25,26}$ on the corneal nerve network after HSV-1 infection. C57BL6 mice were ocularly infected or scarified and left uninfected as controls. Starting 2 hours pi, mice were topically treated with $0.1 \%$ ophthalmic solution DEX or lubricant eye drops as control (VEH) onto their corneas. The impact of DEX treatment on corneal nerves and blood vessels was studied by immunohistochemistry using antibodies against $\beta$ III tubulin (pan neuronal marker) and CD31 (endothelial cell marker), respectively. As previously described for uninfected corneas, ${ }^{23}$ the scarified uninfected mice treated with VEH or DEX displayed a stromal network formed by thick nerve trunks that ramified into smaller and more superficial branches as they progressed from the periphery toward the center of the cornea (Figure 1, A-C). A subbasal network composed by thinner, hairpin-like nerves that projected centripetally and presented a roughly parallel orientation from one another, terminating in free nerve endings, was observed. HSV-1 infection resulted in a loss of corneal nerves at 8 days pi with near complete loss of the subbasal nerve fiber network and invasion with blood vessels originating from the limbus of the cornea. DEX preserved the corneal nerve structure at 8 days pi (Figure 1, C, F and I). The nerve protection correlated with retention of subbasal substance $\mathrm{P}$ positive nerves that normally penetrate the corneal epithelium (Supplemental Figure S1). No significant differences in corneal nerves or blood vessels were observed between groups at earlier time points, as revealed by analysis at 2 and 4 days pi (Figure 1, A, B, D, E, G and H). Consistent with the anti-inflammatory activities of glucocorticoids, infected corneas treated with DEX appeared healthy and clear compared to VEH-treated, HSV1-infected corneas (Supplemental Figure S2). The profound loss of corneal nerves (thick stromal and thin subbasal) observed in infected corneas treated with VEH was associated with a significant loss of corneal sensitivity at 8 days pi. DEX treatment resulted in significant preservation of corneal function by day 8 pi (Figure $1 \mathrm{~J}$ ). The effect of DEX on corneal viral contents was measured at different times pi by plaque assay. At 2 days pi, DEX significantly decreased the infectious virus recovered in the cornea compared to VEH-treated corneas. However, at 4 and 8 days pi, no differences in the viral load were appreciated between groups (Figure $1 \mathrm{~K}$ ). As revealed by Western blot analysis, the decreased infectious viral content at 2 days pi in the DEX-treated group did not correlate with decreased expression of HSV entry receptors herpes virus entry mediator or nectin-1 in the cornea tissue (Supplemental Figure S3).

\section{Effect of DEX Treatment on the Immune Response to HSV-1 Infection in the Cornea}

To elucidate possible phenotypic changes in the immune cell infiltrate to HSV-1 infection that could relate to the protective effect of topical DEX treatment on corneal innervation, we conducted flow cytometric analysis for detection of myeloid-derived and $\mathrm{T}$ cells in infected corneas at different time points pi. Data revealed DEX treatment decreased the cell count of macrophages in the corneas at all time points analyzed (2, 4, and 8 days pi). At 2 and 4 days pi, the PMN cell count was significantly increased in the DEX-treated corneas compared to the VEH-treated group.

\footnotetext{
Figure 1 Dexamethasone prevents corneal nerve regression and function loss after HSV-1 infection. Mouse corneas were infected with $10^{3}$ plaque-forming units (PFUs) HSV-1, or left uninfected (UI) as scarified (sc UI), or non-scarified (naive) controls. Starting at 2 hours post infection (pi), mice were topically treated with DEX or VEH onto their corneas (four applications of one drop each day, at periods of time between 7 AM and 7 PM) for 2, 4, or 8 days pi before tissue collection. A-C: Representative confocal images show corneal nerves (green: $\beta$ III tubulin staining) and vessels (red: CD31 staining; top discontinued white lines depict the limbal margins) at $2(\mathbf{A}), 4(\mathbf{B})$, and 8 (C) days pi. Analysis of corneal innervation (D-F) and vascularization (G-I) at the indicated time points pi expressed as mean percentage threshold area positive for $\beta$ III tubulin signal per field of view and mean percentage threshold area positive for CD31 signal per field of view, respectively, from two to four independent experiments. J: Bars show mean Cochet-Bonnet score (from two to seven independent experiments). K: Viral content in the corneas at different time points pi. Viral titer in corneas at 2, 4, and 8 days pi measured by plaque assay (from two independent experiments). Data are given as means \pm SEM (D-K). $n=8$ to 11 per infected group (D-F); $n=4$ to 7 per infected group (G-I); $n=4$ to 6 per UI group (D-I); $n=4$ to 10 per UI group (J); $n=14$ to 35 per infected group (J); $n=6$ to 7 per group (K). * $P<0.05$, ** $P<0.01$, and ${ }^{* * *} P<0.001$ versus HSV-1 + VEH group at 8 days pi by analysis of variance, followed by Bonferroni multiple comparison test; $\dagger^{\dagger \dagger} P<0.001$ versus HSV-1 + VEH group at 2 days pi by unpaired $t$ test comparison. Scale bars $=200 \mu \mathrm{m}(\mathbf{A}-\mathbf{C})$.
} 


\section{A}
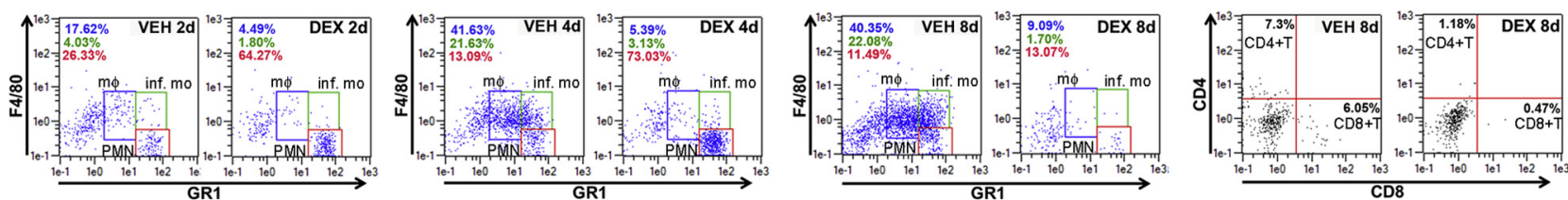

B
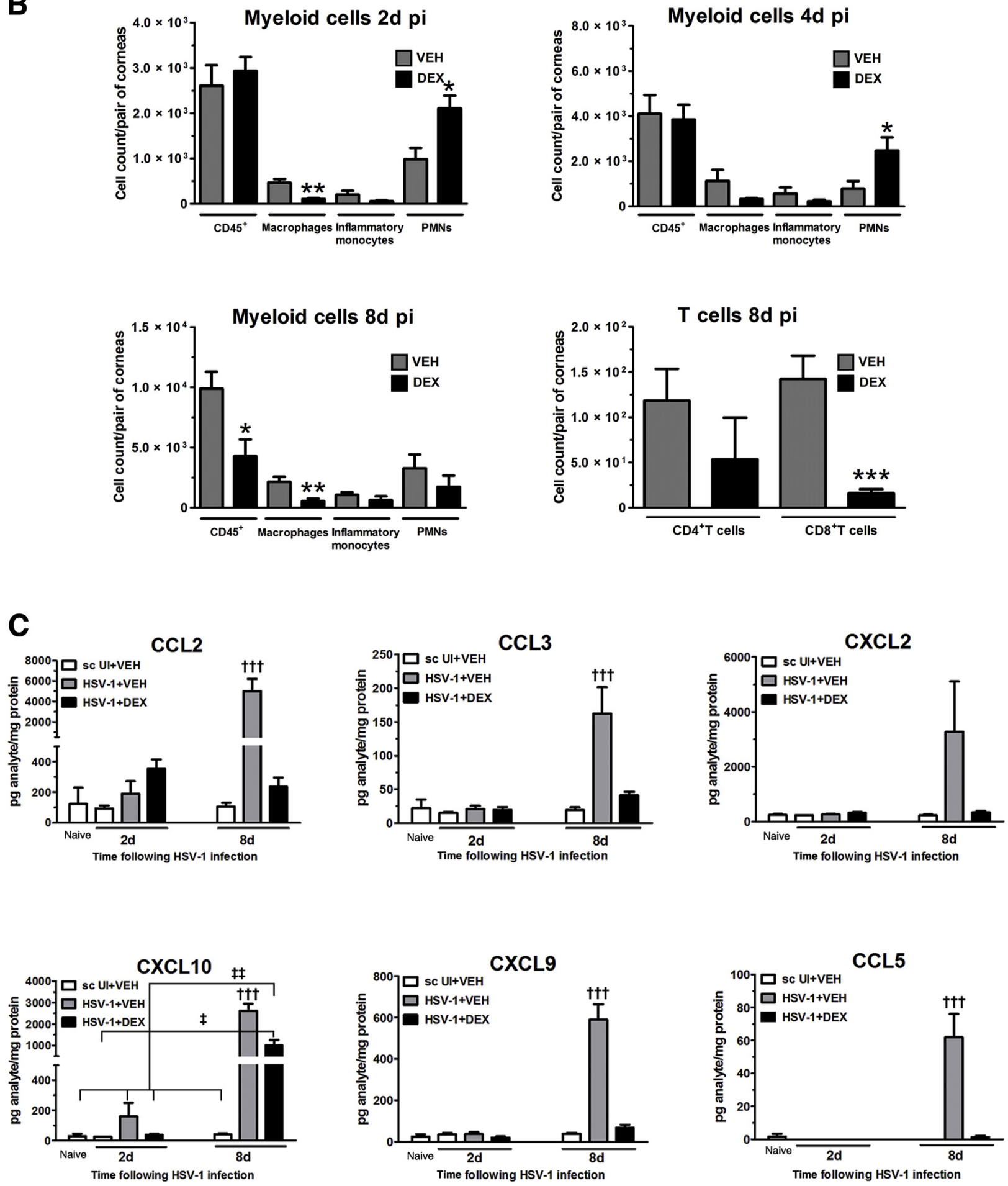
At 8 days pi, when the adaptive immune cell infiltrate was analyzed, $\mathrm{CD} 8^{+} \mathrm{T}$ cell numbers were significantly reduced and the overall leukocyte infiltrate, along with PMNs, was significantly reduced by DEX (Figure 2, A and B). The expression of selective chemokines that recruit inflammatory cells to the site of infection was greatly reduced by DEX treatment at 8 days pi. An increase in the contents of CCL2, CCL3, CCL5, CXCL2, CXCL9, and CXCL10 previously reported in the cornea during acute HSVlinfection, ${ }^{32}$ expressed in the infected group treated with VEH, was suppressed by DEX treatment by 8 days pi (Figure 2C). DEX treatment did not completely reduce CXCL10 expression at 8 days pi (Figure 2C).

\section{The Effect of DEX on Preserving Corneal Nerves Likely Involves the Down-Regulation of Proinflammatory Pathways}

Two alternative but not mutually exclusive processes to explain the mechanism of nerve preservation in corneas treated with DEX are enhanced proneurogenic signaling and/ or down-regulation of proinflammatory pathways that are detrimental to neuronal structure and function. Neurotrophins, which include the NGF family, GDNF family ligands, and a heterogeneous group of factors that belong to the cytokine family, have a proneurogenic role during neural regeneration, remyelination, and development of the peripheral and central nervous systems. ${ }^{33}$ Members of the neurotrophin family found to be expressed in the cornea, ${ }^{1,34}$ up-regulated after lamellar flap surgery, ${ }^{35}$ and in keratoconus ${ }^{36}$ are likely part of the corneal nerve regeneration process. To address whether the preservation of corneal innervation by DEX involved enhanced neurotrophin signaling, the transcript levels of candidate neurotrophins, including NGF, NTF3, NTF5, brain-derived neurotrophic factor, GDNF, ciliary neurotrophic factor, and leukemia inhibitory factor, were measured in samples from corneas treated with VEH or DEX at 2 and 8 days pi by real-time quantitative PCR. Our data analysis supported no role for the neurotrophin signaling as a mechanism of nerve preservation by DEX (Figure 3A). Although the expression of NGF and leukemia inhibitory factor transcripts was significantly increased in the infected group treated with VEH, such increases were suppressed in
DEX-treated, infected mice. A similar trend was observed for GDNF transcript (Figure 3A).

Proinflammatory cytokines driven by the transcription factor NF- $\mathrm{BB}$ are produced by epithelial infected cells as well as inflammatory leukocytes in response to HSV-1 infection. ${ }^{16,22,31}$ The anti-inflammatory effects of glucocorticoids, such as DEX, are largely considered to be exerted through cross talk with proinflammatory signaling pathways, including NF- $\kappa \mathrm{B} .{ }^{37,38}$ The analysis of two NF- $\kappa \mathrm{B}-$ driven cytokine genes, associated with the immunosuppressive action of DEX, IL-6, and IL-1 $\beta$, showed a strong trend toward up-regulation at 2 and 8 days pi (Figure 3A). This increased expression was blocked on DEX treatment (Figure 3A). To further characterize the involvement of increased inflammatory pathways in the nerve regression after HSV-1 infection, we analyzed the protein levels from a panel of NF- $\kappa \beta$-driven cytokines relevant to HSV-1 infection in the cornea, including IL- $1 \alpha$, IL-1 $\beta$, IL-2, IL-4, IL-6, IL-12, IL-17, IFN- $\gamma$, and tumor necrosis factor- $\alpha^{16,31,39,40}$ at 2 and 8 days pi. HSV-1 infection greatly increased the corneal content of IL-6, IFN$\gamma$, and IL- $1 \alpha$ proteins in the group treated with VEH. DEX treatment blocked such increases (Figure 3B). Unlike what was observed at the transcript level at 8 days pi (Figure 3A), no trend toward a decrease of IL- $1 \beta$ protein was observed in the DEX-treated corneas compared to the VEH-treated group. No other analytes surveyed were found to be detected above background levels at these time points (data not shown).

\section{The Nerve Preservation by DEX Is Lost When the Treatment Is Delayed}

The protective effect of DEX on the corneal innervation was found to be time-dependent because it was lost on delaying the treatment. Specifically, when the topical steroid treatment began at 2 days pi instead of at 2 hours pi, both the percentage threshold area positive for $\beta$-III tubulin staining in the cornea (Figure 4, A and B) and the corneal sensitivity score (Figure 4C) were not significantly different between DEX- and VEH-treated groups measured at 8 days pi. The delay of DEX treatment (treatment from 2 to 8 days) showed no significant impact on the amount of virus recovered from corneas at 8 days pi, compared to the VEHtreated counterparts and to mice treated with VEH or DEX starting at 2 hours pi (treatment from 0 to 8 days)

Figure 2 Dexamethasone effect on immune cell infiltrate and chemokine expression in the cornea after HSV-1 infection. Mouse corneas were infected with $10^{3}$ plaque-forming units HSV-1, or left uninfected (UI) as scarified (sc UI), or non-scarified (naive) controls. Starting at 2 hours post infection (pi), mice were topically treated with DEX or VEH onto their corneas for 2, 4, or 8 days pi before tissue collection. A and B: Infected corneas were harvested from mice and single-cell suspensions from the tissue were stained with specific monoclonal antibodies to phenotypically identify the leukocyte influx. A: Representative flow cytometry plots from infected corneas treated with VEH (left column) or DEX (right column) for 2, 4, and 8 days pi. Values inside the F4/80 versus GR1 plots indicate percentages of macrophages (blue text), inflammatory monocytes (green text), and polymorphonuclear cells (PMNs; red text). Values inside the CD4 versus CD8 plots indicate the percentages of $\mathrm{CD}^{+}$and $\mathrm{CD}^{+} \mathrm{T}$ cells. B: Data summarize the mean phenotypic leukocyte count, from two independent experiments. C: Concentration of chemokines CCL2, CCL3, CCL5, CXCL2, CXCL9, and CXCL10 was measured in corneal protein extracts at 2 and 8 days pi by suspension array. Bars depict the mean $\mathrm{pg} / \mathrm{mg}$ protein concentration for each analyte (from two independent experiments). Data are given as means \pm SEM (B and $\mathbf{C}) . n=6$ per 2 days pi group (B); $n=4$ to 5 per 4 days pi group (B); $n=9$ to 10 per 8 days pi group (B); $n=3$ to 5 per UI group (C); $n=5$ to 6 per infected group $(\mathbf{C}) .{ }^{*} P<0.05,{ }^{* *} P<0.01$, and ${ }^{* * *} P<0.001$ versus HSV-1 + VEH group by unpaired $t$ test comparison; ${ }^{\dagger \dagger \dagger} P<0.001$ versus the rest of the groups; ${ }^{\ddagger} P<0.05,{ }^{\ddagger \ddagger} P<0.01$ versus HSV-1 + DEX group at 8 days pi by analysis of variance, followed by Bonferroni multiple comparison test. 

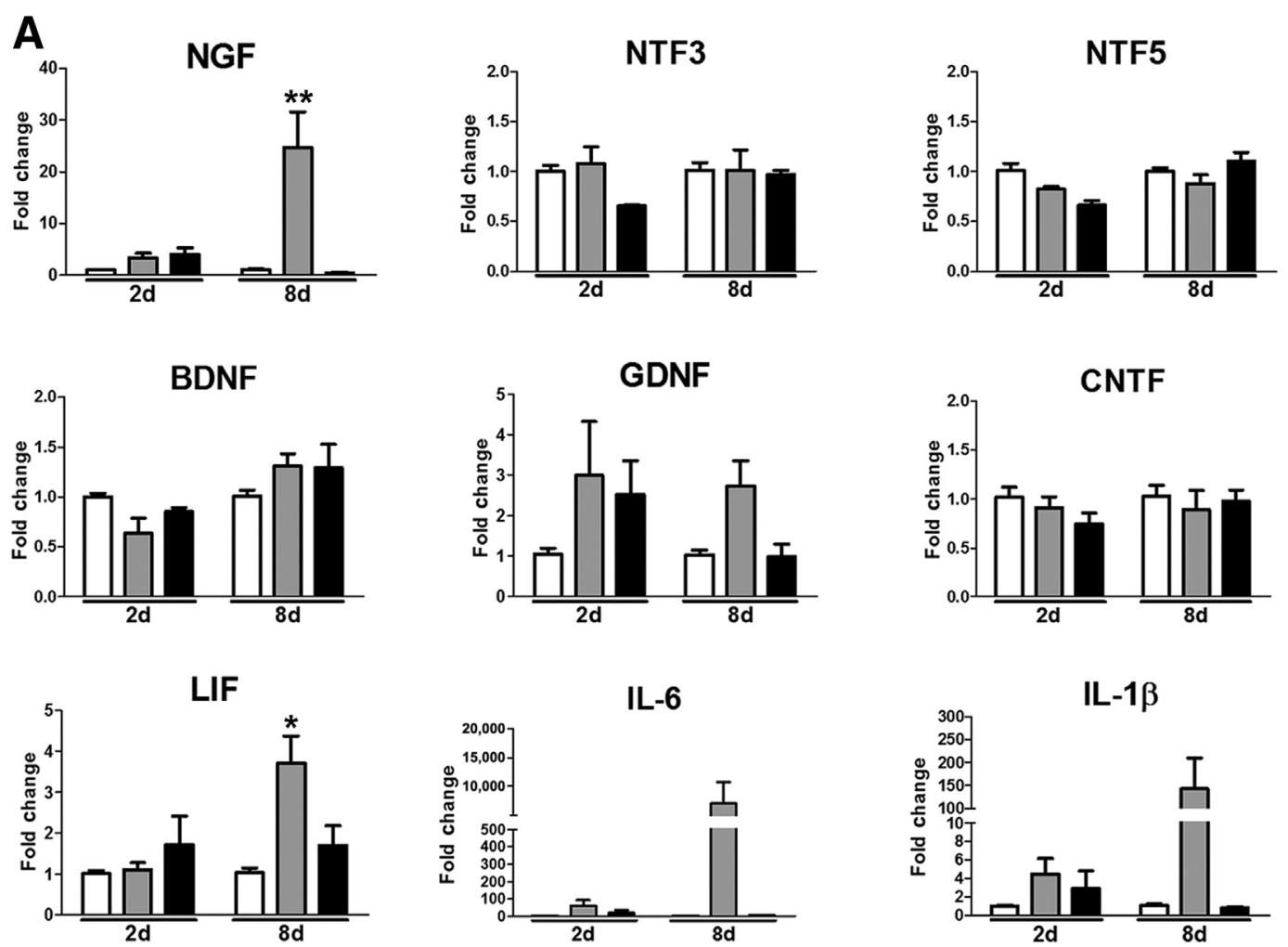

UI $\square$ HSV-1+VEH $\square$ HSV-1+DEX

B

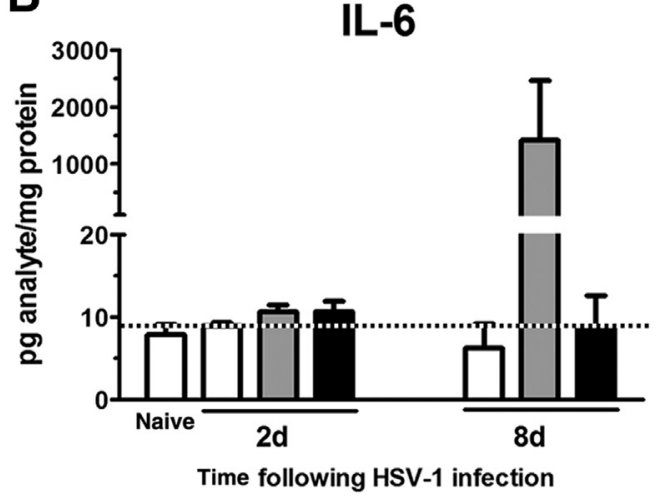

IL-1 $\alpha$

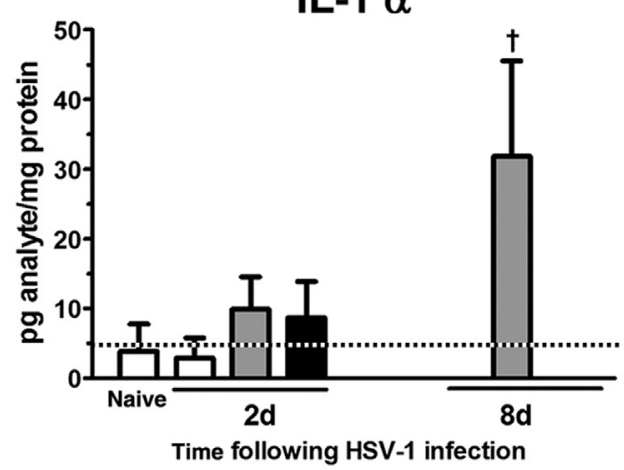

IFN- $\gamma$

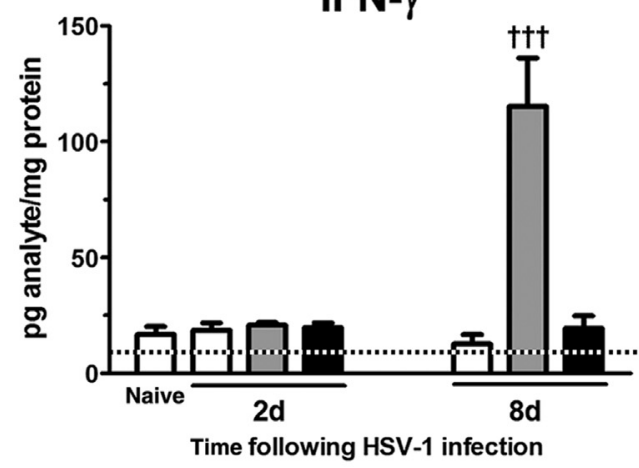

IL-1 $\beta$

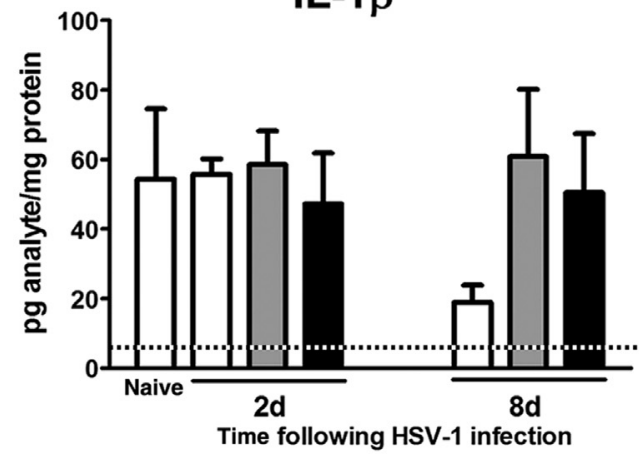


(Figure 4D). Protein analysis of inflammatory cytokines at 8 days pi showed, unlike what was observed after early intervention (Figure 3B and Figure 4E), a delay of 2 days to start DEX treatment resulted in no significant decrease of IL-6 in the infected corneas (Figure 4E). Of interest, IFN- $\gamma$ was partially but not significantly reduced, and IL- $1 \alpha$ was significantly reduced in the infected corneas subjected to delayed DEX treatment. These observations support the notion that early events in response to HSV-1 infection are key in driving corneal nerve loss in this model and reinforce the hypothesis that inflammation, through the production of soluble mediators, such as IL-6, contributes to the degenerative process.

\section{Neutralization of IL-6 Results in Significant Preservation of Corneal Nerve Function that Correlates with Retention of Fine Subbasal Nerves}

Increased IL-6 signaling is thought to be a mediator of HSV1 -induced corneal pathogenesis. ${ }^{40-42}$ To address whether the increase of IL- 6 protein concentration after HSV-1 infection was responsible for corneal nerve degeneration, we conducted experiments to locally neutralize IL-6. Subconjunctival delivery of neutralizing antibody against IL-6 during the first 6 days pi resulted in a significant loss of IL-6 protein compared to the infected, IgG-treated group. On the other hand, treatment of infected corneas with anti-IL-6 did not result in statistically significant differences in the contents of IFN- $\gamma$ and IL- $1 \alpha$ compared to the infected, IgGtreated group. Of notice, although a trend toward decrease of IL-1 $\beta$ after anti-IL- 6 treatment was observed, there was not statistical difference between the IgG- and anti-IL-6 treated groups (Figure 5A). As expected, IgG isotype control or untreated infected corneas displayed a noticeable loss in cornea sensitivity after HSV-1 infection (Figure 5B). By comparison, anti-IL-6 antibody treatment partially preserved corneal sensitivity (Figure 5B). The functional preservation in the anti-IL-6-treated group was sustained and greater at 8 days pi (Figure 5B). By immunohistochemistry analysis, corneas of infected mice that received anti-IL-6 antibody showed significant preservation of the corneal nerve network, specifically at the level of the subbasal fine bundles (subepithelial) (Figure 5, C and D), and a modest trend toward decreased vascularization compared to their infected, IgG-treated controls (Figure 5E).

\section{Effect of Local Neutralization of IL-6 on the Immune} Cell Infiltrate and Viral Content in the Cornea

Because IL-6 is an important factor in recruiting inflammatory cells to the site of infection, ${ }^{43}$ and a deficiency in expression is associated with enhanced susceptibility to HSV $-1,{ }^{44}$ we evaluated the effect of IL-6 neutralization on leukocyte influx and viral content in the cornea after HSV-1 infection. The results showed that IL-6 neutralization did not have a significant impact on the myeloid or T-cell influx into the cornea (Figure 6A), which we interpret to suggest targeting IL-6 alone is insufficient to alter the influx of leukocytes to the infected tissue, likely because of cytokine redundancy. On the other hand, local IL-6 neutralization resulted in a significantly higher viral load at 8 days pi compared to the IgG-treated group (Figure 6B). Viral titers at 2 days pi were not found to be different between IL-6- and Ig-G-treated groups (Figure 6B).

\section{Discussion}

The idea that immune components play a role in the preservation of corneal nerves ${ }^{45}$ or influence the long-term persistence of their defects after herpetic infection ${ }^{22}$ has been recently suggested. Our study offers novel mechanistic insights that link the elicited immune response to HSV-1 infection, and not local viral replication, as the explanation for corneal nerve regression after infection. Furthermore, IL-6 is one soluble factor expressed during corneal HSV-1 infection on which neutralization reduces nerve regression and partially preserves corneal sensation.

The use of steroids in the management of NTK is controversial because all topical medications are contraindicated because of the potential detrimental effects on the ocular surface. ${ }^{4}$ Specific to HSV-1 infection, steroid treatment has been shown to reactivate latent infection in a variety of experimental models. ${ }^{46-49}$ In the clinical setting, topical corticosteroid therapy is recommended only in combination with antiviral therapy to reduce viral reactivation. ${ }^{50}$ In the present study, data support a timedependent beneficial effect of immunosuppression on the sensory innervation of the cornea in the absence of antiviral drug intervention. We found topical treatment with DEX resulted in the preservation of corneal sensory fibers and

\footnotetext{
Figure 3 Effect of dexamethasone on the expression of neurotrophins and inflammatory cytokines after HSV-1 infection. Mouse corneas were infected with $10^{3}$ plaque-forming units HSV-1 or left uninfected (UI) as scarified (sc UI), or non-scarified (naive) controls. Starting at 2 hours post infection (pi), mice were topically treated with DEX or VEH onto their corneas for 2 or 8 days pi before tissue collection. A: Corneas were processed for RNA isolation, cDNA synthesis, and RT-PCR analysis of selected neurotrophins [nerve growth factor (NGF), neurotrophin (NTF)3, NTF5, brain-derived neurotrophic factor (BDNF), glial cell line-derived neurotrophic factor (GDNF), ciliary neurotrophic factor (CNTF), and leukemia inhibitory factor (LIF)] and proinflammatory cytokines (IL-6 and IL$1 \beta$ ). Results are expressed as mean fold change relative to UI (from two independent experiments). B: Cornea protein extracts were analyzed for inflammatory cytokine content by suspension array. Bars depict the mean $\mathrm{pg} / \mathrm{mg}$ protein concentration for each analyte (from two independent experiments). Dotted lines depict the threshold of detection for each analyte normalized to the average protein content in the samples. Data are given as means \pm SEM $(\mathbf{A}$ and $\mathbf{B}) . n=4$ to 6 per UI group (A); $n=3$ to 6 per infected group (A); $n=3$ to 5 per UI group (B); $n=6$ per infected group (B). ${ }^{*} P<0.05,{ }^{* *} P<0.01$ versus the rest of the groups under the same time point by analysis of variance, followed by Bonferroni multiple comparison test; ${ }^{\dagger} P<0.05,{ }^{\dagger \dagger \dagger} P<0.001$ versus the rest of the groups by analysis of variance, followed by Bonferroni multiple comparison test.
} 

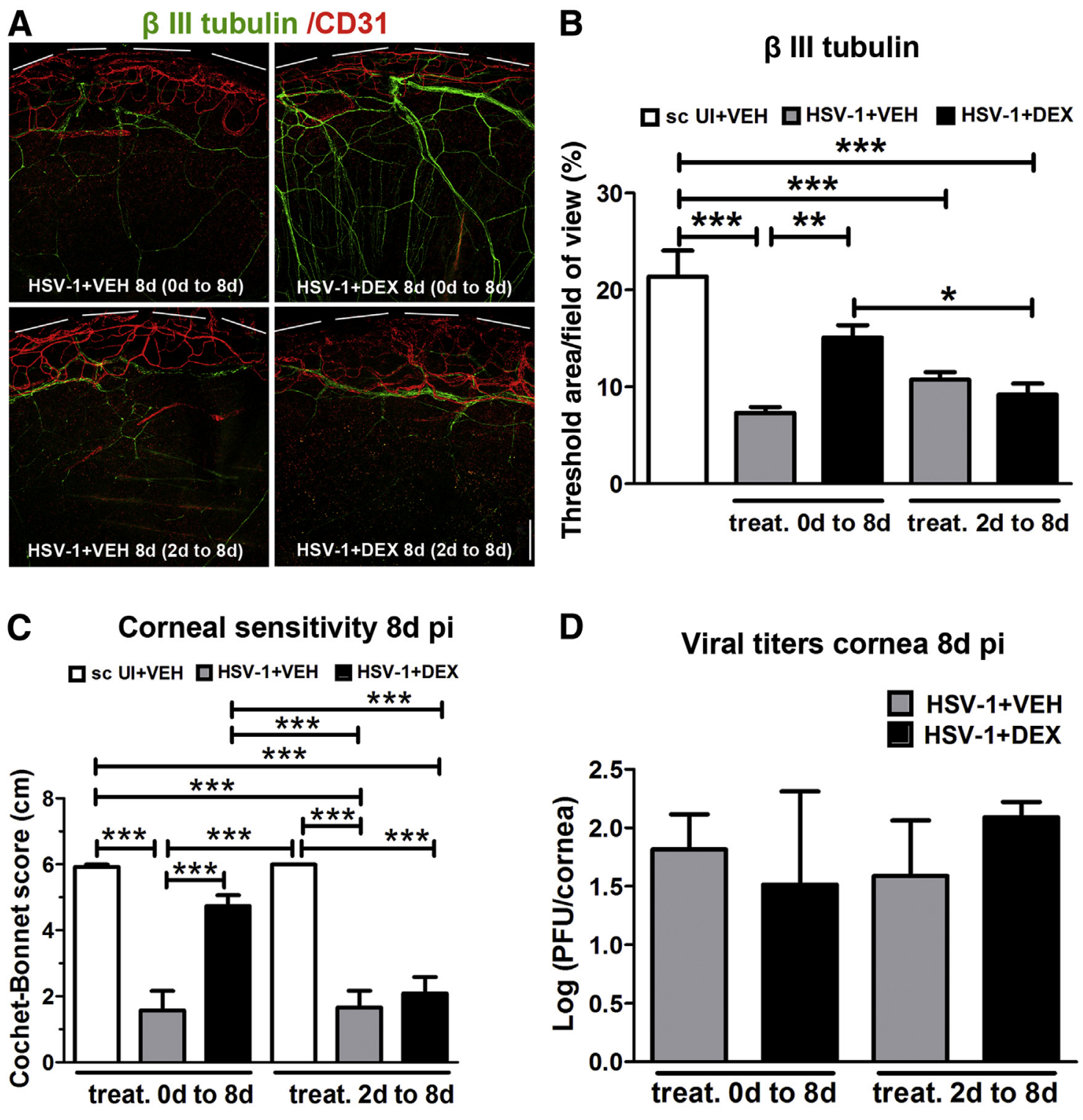
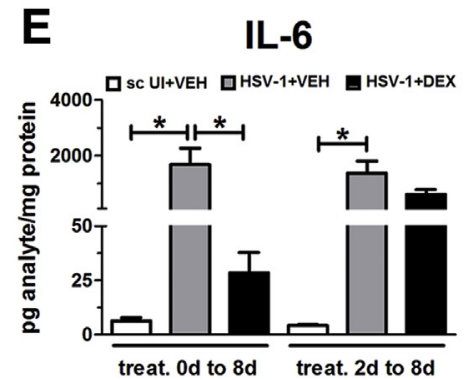

IFN- $\gamma$

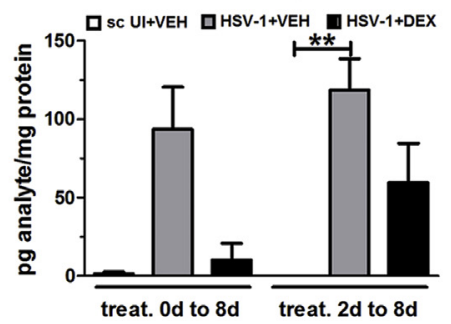

IL-1 $\alpha$

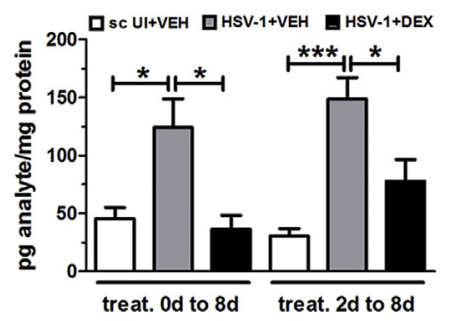

Figure 4 The nerve preservation by dexamethasone is lost when the treatment (treat.) is delayed. Mouse corneas were infected with $10^{3}$ plaque-forming units HSV-1, or left uninfected (UI) as scarified (SC UI) controls. Mice were topically treated with DEX or VEH onto their corneas starting at 2 hours post infection (pi) (treatment 0 to 8 days), or starting 2 days pi (treatment 2 to 8 days) until tissue collection at 8 days pi. A: Representative confocal images of infected corneas subjected to early or delayed topical treatment as indicated above (green: $\beta$ III tubulin staining; red: CD31 staining; top discontinued white lines depict the limbal margins). B: Analysis of corneal innervation expressed as mean percentage threshold area positive for $\beta$ III tubulin signal per field of view (from three independent experiments). C: Mean corneal sensitivity score measured for experimental groups (from four independent experiments). D: Viral content in the infected corneas comparing different topical treatments. Bars show mean viral contents in corneas at 8 days pi measured by plaque assay (from two independent experiments). E: Protein content of IL-6, interferon (IFN)- $\gamma$, and IL-1 $\alpha$ in cornea samples measured by suspension array. Bars depict the mean $\mathrm{pg} / \mathrm{mg}$ protein concentration for each analyte (from two independent experiments). Data are given as means \pm SEM (B-E). $n=5$ to 12 per group (B); $n=4$ to 8 per sc UI group (C); $n=8$ to 22 per infected group (C); $n=3$ per 0 to 8 day treated group (D); $n=5$ per 2 to 8 day treated group (D); $n=5$ to 7 per group (E). ${ }^{*} P<0.05,{ }^{*} P<<0.01$, and ${ }^{* *} P<0.001$ by analysis of variance, followed by Bonferroni multiple comparison test. Scale bar $=200 \mu \mathrm{m}$. 
A
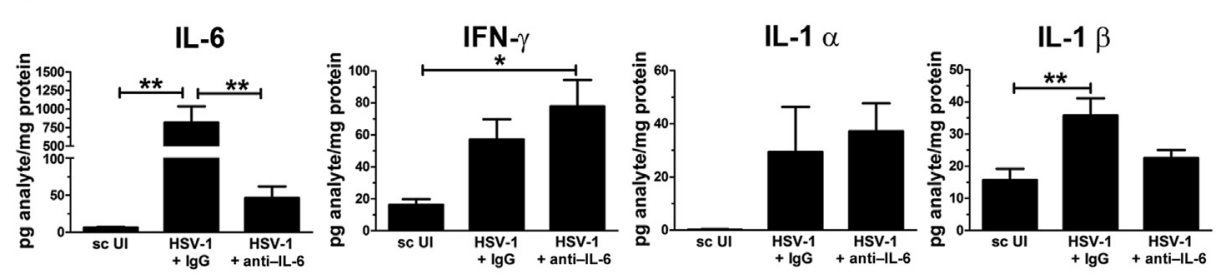

C

$\beta$ III tubulin/CD31
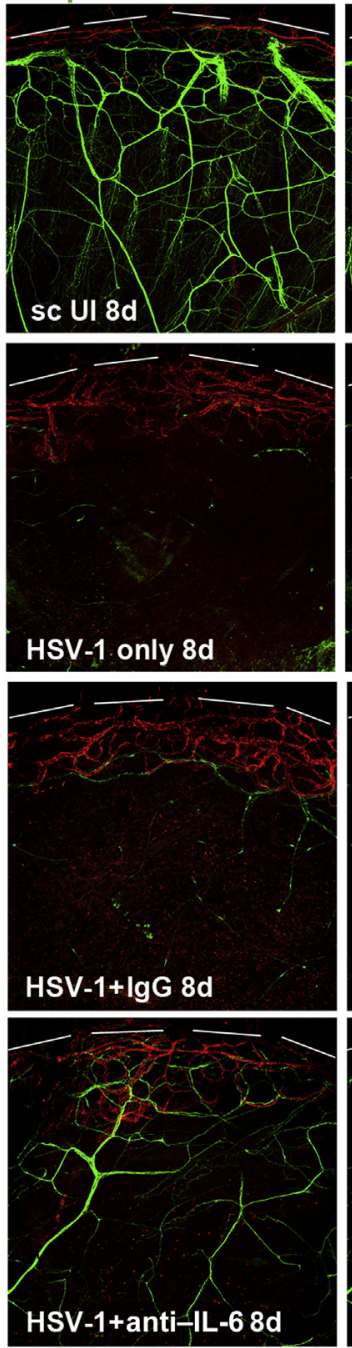

$\beta$ III tubulin
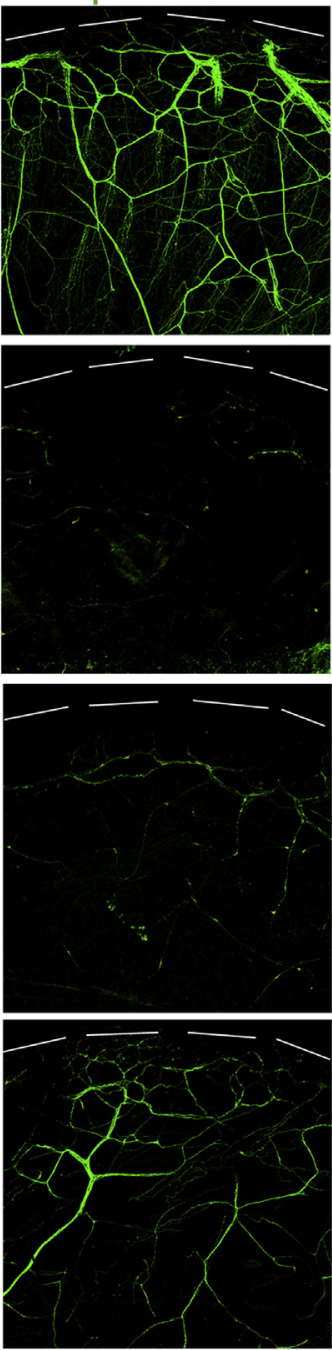

$\beta$ III tubulin SE
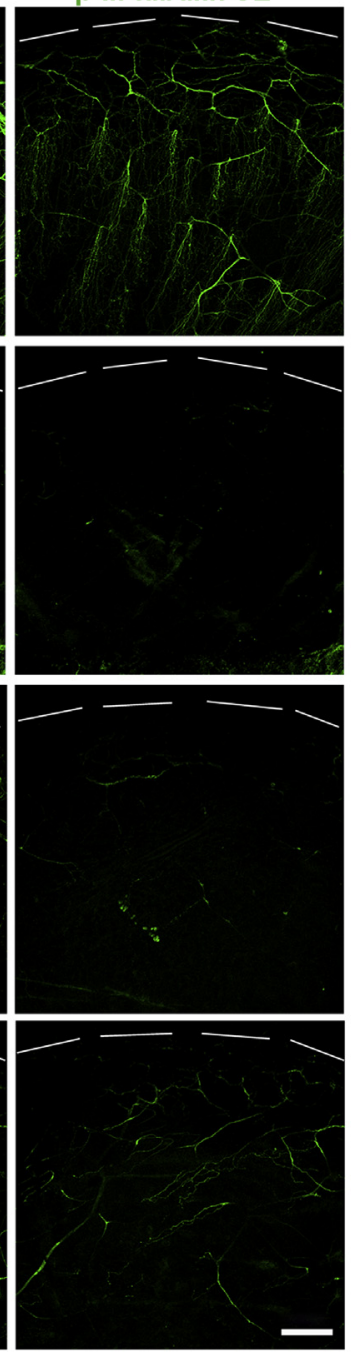

B Corneal sensitivity

$\begin{array}{ll}\text { 口 } \mathrm{sc} \text { UI } & \text { HSV-1+lgG } \\ \text { HSV-1 only } & \text { HSV-1+anti-IL-6 }\end{array}$

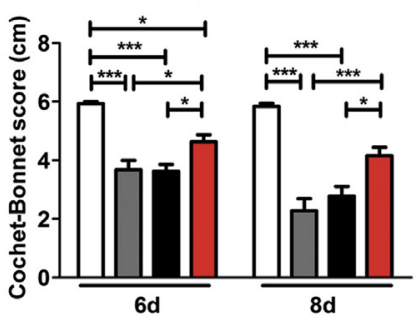

D $\quad \quad \quad \quad$ III tubulin 8d
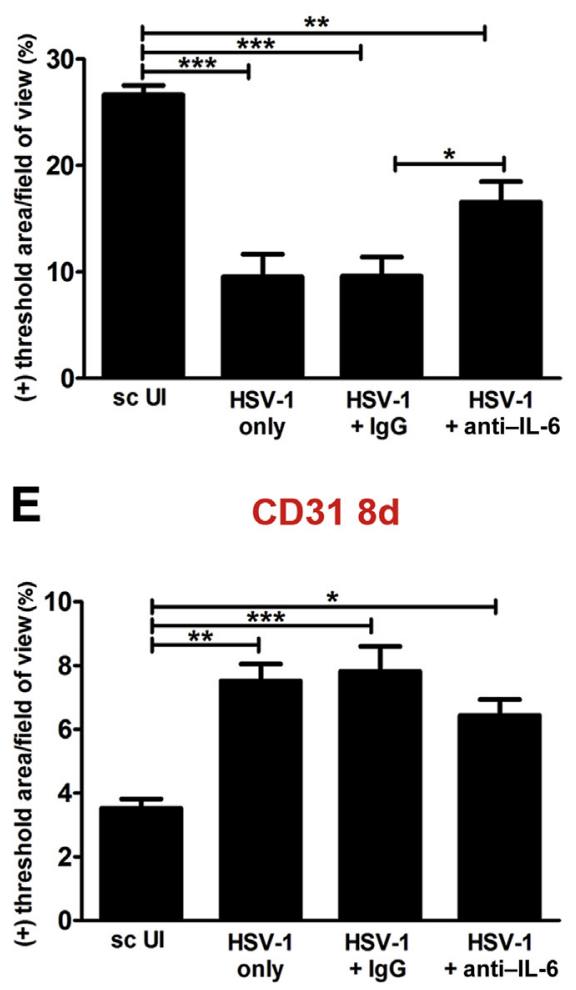

Figure 5 Neutralization of IL-6 results in significant preservation of corneal nerve function that correlates with retention of fine subbasal nerves. Mouse corneas were infected with $10^{3}$ plaque-forming units HSV-1, or left uninfected (UI) as scarified controls (sc UI). Starting at 1 hour post infection (pi), infected mice were given subconjunctival injections of $5 \mu \mathrm{g}$ of anti-IL-6 or isotype control (normal goat IgG) antibody at repeated doses every 2 days until 6 days pi. At 8 days pi, corneas were harvested for protein assay (suspension array) and immunohistochemical analysis. A: Protein content of IL-6, interferon (IFN)- $\gamma$, IL$1 \alpha$, and IL- $1 \beta$ in cornea homogenates at 8 days pi after the described treatments. Bars depict the mean $\mathrm{pg} / \mathrm{mg}$ protein concentration for the measured analytes (for IL- 6 and IFN- $\gamma$, from four independent experiments, and for IL- $1 \alpha$ and IL-1 $\beta$, from two independent experiments). B: Bars show mean CochetBonnet score at 6 and 8 days pi for the indicated experimental groups. C: Representative confocal images displayed as merged signal of $\beta$ III tubulin and CD31 (left column), and as $\beta$ III tubulin signal alone (middle column). The right column display the Z-stack confocal data corresponding to the subbasal nerve network (green: $\beta$ III tubulin staining; red: CD31 staining; top discontinued white lines depict the limbal margins). Analysis of corneal innervation (D) and vascularization $(\mathbf{E})$ at 8 days pi expressed as mean percentage threshold area positive for $\beta$ III tubulin signal per field of view and mean percentage threshold area positive for CD31 signal per field of view, respectively (from two independent experiments). Data are given as means \pm SEM (A, B, D, and E). $n=6$ to 10 per IL- 6 and IFN- $\gamma$ group $(\mathbf{A}) ; n=4$ to 6 per IL- $1 \alpha$ and IL-1 $\beta$ group $(\mathbf{A}) ; n=4$ to 8 per group $(\mathbf{D}$ and $\mathbf{E})$. ${ }^{\star} P<0.05,{ }^{* *} P<0.01$, and ${ }^{* * * P} P 0.001$ by analysis of variance, followed by Bonferroni multiple comparison test. Scale bar $=200 \mu \mathrm{m}$. 


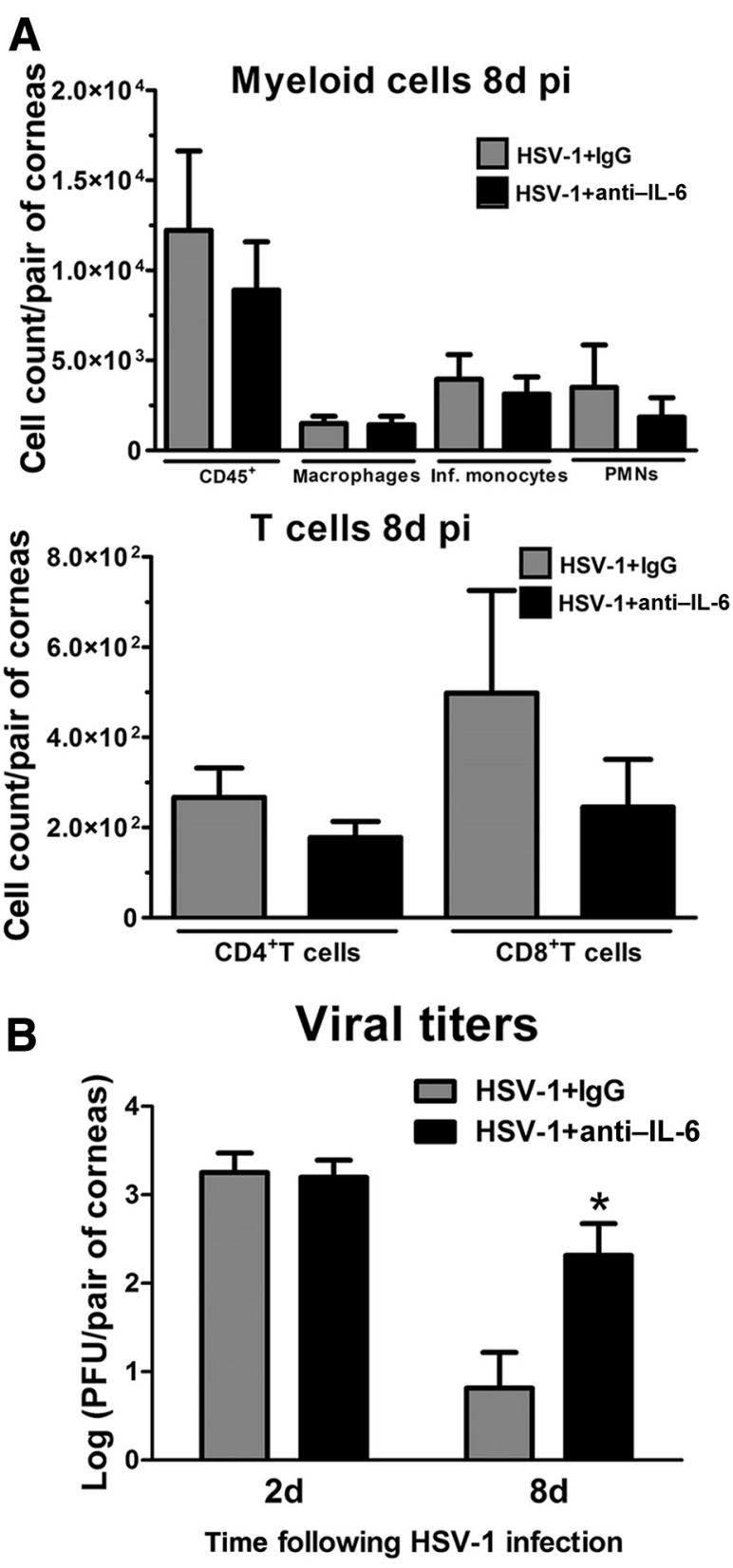

Figure 6 Corneal immune cell infiltrate and viral content after neutralization of IL-6. Mouse corneas were infected with $10^{3}$ plaque-forming units HSV-1. Starting at 1 hour post infection (pi), mice were given subconjunctival injections of $5 \mu \mathrm{g}$ anti-IL- 6 or isotype control (normal goat IgG) antibody at repeated doses every 2 days until 6 days pi. A: Phenotype of the myeloid and T-cell infiltrate in infected corneas at 8 days pi as measured by flow cytometry. Data summarize the mean phenotypic leukocyte count, from two independent experiments, analyzed by unpaired $t$ test comparison. B: Bars show mean viral contents in corneas at 2 and 8 days pi measured by plaque assay (from two independent experiments). Data are given as means \pm SEM (A and $\mathbf{B}$ ). $n=5$ to 6 per group $(\mathbf{A}) ; n=5$ per group $(\mathbf{B}) .{ }^{\star} P<0.05$ versus HSV $-1+\mathrm{IgG}$ group at 8 days pi by unpaired $t$ test comparison. Inf., inflammatory; PMNs, polymorphonuclear cells.

their sensitivity during the acute phase of HSV-1 infection. Such protection was consistent with the antiangiogenic properties known to be exerted by this drug in the cornea. ${ }^{24}$ The nerve structure and functional preservation by DEX occurred in the context of decreased cell counts of macrophages at all time points studied and decreased $\mathrm{CD} 8^{+} \mathrm{T}$ cells at 8 days pi. An unexpected outcome was the transiently elevated presence of PMNs in the infected corneas treated with DEX, compared to the control group. Other studies have also described elevation of myeloid cells consistent with PMN phenotype after steroid treatment in corneal tissue. ${ }^{24,51,52}$ However, considering the known implications of PMNs in the pathology in response to HSV $-1,{ }^{53}$ the role of this shift in the local immune cell constituency is not understood.

A previous in vitro study described a differential effect of DEX on viral yield depending on the timing of treatment relative to HSV-1 infection. ${ }^{38}$ With our in vivo model of HSV-1 infection, we found DEX treatment coincided with a reduced level of virus recovered from the tissue at an early time point ( 2 days pi). However, at 4 and 8 days pi, the viral load in both DEX- and VEH-treated groups was not significantly different. The early reduced viral replication was not associated with receptor expression by corneal cells because the expression of herpes virus entry mediator and nectin-1 HSV receptors was not different between DEX- and VEH-treated corneas at 2 days pi (Supplemental Figure S3). We speculate the delay in virus replication in DEX-treated corneas may be because of changes in the metabolic machinery of corneal epithelial cells. We consider this a feasible explanation given the complex effects of glucocorticoids on metabolism, including altered glucose synthesis, suppression of cell proliferation and protein synthesis, and inhibition of $\mathrm{Na}^{+} / \mathrm{K}^{+}$-ATPase. ${ }^{54} \mathrm{To}$ address whether the cause of corneal nerve preservation by topical DEX treatment was its effect delaying the establishment of infection during the first 2 days pi (Figure $1 \mathrm{~K}$ ) or its immunosuppressive actions in the cornea, we studied the effect of changing the route of DEX delivery on early viral replication and corneal sensitivity. We found that i.p. delivery of DEX showed similar trend of effect on corneal inflammatory infiltrate as the topical treatment (not shown), whereas it did not affect the corneal viral titers at 2 days pi compared to its control phosphate-buffered saline treatment, and provided functional nerve preservation by day 6 pi (Supplemental Figure S4A), a time point in which topical delivery of DEX started showing efficacy preventing loss of corneal sensitivity (Supplemental Figure S4B). These observations support the idea that in the milieu of the infected cornea it is the elicited immune response and not local viral replication itself that affects corneal nerve regression.

Our findings correlate IL-6 and IFN- $\gamma$ levels in the infected corneas with denervation. Suppression of soluble IL-6 expression resulted in retention of corneal stromal and subbasal nerve networks and maintenance of corneal sensitivity. IL-6 is a pleiotropic cytokine that signals through the membrane-bound IL-6 receptor (R), leading to the activation and dimerization of the signal transduction protein 130 (gp130). Alternatively, via a trans-signaling pathway, IL-6 
binds to soluble IL-6R and the IL-6/SIL-6R complex activates gp $130 .^{55,56}$ Through both classic and trans-signaling pathways, described in the cornea during inflammation, ${ }^{57}$ IL-6 signals via the tyrosine-protein kinase JAK2 and STAT3 to modulate the transcription of genes linked to the cell cycle, inflammation, apoptosis, cytokine signaling, and lipid metabolism. ${ }^{58}$ Local neutralization of IL-6 revealed IL-6 functions as one of the mediators of nerve degeneration because its deficiency in the infected cornea resulted in partial preservation of corneal sensitivity, which correlated with modest retention of fine subbasal bundles of nerves. We consider possible that increased IFN- $\gamma$ signaling might have a synergistic effect with IL-6. On binding to and activating its specific receptors, IFN- $\gamma$ is capable of activating the downstream STAT1 and STAT3 pathways and can divert IL-6 signaling to the STAT1 pathway. ${ }^{59}$

A recent report described a mechanism of corneal nerve loss that is inconsistent with our findings reported herein. ${ }^{45}$ By making use of mouse models of dendritic cell depletion and deficient leukocyte infiltration, Hu et $\mathrm{al}^{45}$ concluded that the corneal nerve loss in primary herpes simplex keratitis is because of viral replication and not leukocyte infiltration. Collectively, our data support the observation that elicited immune response to infection promotes denervation. The observation that neutralization of IL-6 in the cornea had no effect on viral replication at 2 days pi (when topical DEX treatment had an effect decreasing viral titers) and significantly increased viral content by 8 days pi supports the hypothesis that the nerve regression process is not triggered by the virus itself replicating in the cornea. We submit the loss of nerves in response to local HSV-1 infection is because of a combination of events, including proinflammatory factors secreted by resident hematopoietic and/ or nonhematopoietic-derived cells. IL-6R, soluble IL-6R, and gp130 are expressed in the cornea, ${ }^{57}$ and the gp130 receptor is thought to be ubiquitously expressed in sensory neurons. ${ }^{60}$ Thus, we speculate that the mechanism of corneal nerve regression after infection might involve direct action of local IL- 6 on cells present in the cornea (resident and/or infiltrating immune cells), and/or IL-6 triggered signaling within sensory neurons innervating the tissue. Whether HSV-1 infection of sensory neurons in the trigeminal ganglia plays a role in the degeneration of corneal nerves remains unknown and should be further explored.

\section{Acknowledgments}

We thank Derek Royer, Hem Gurung, and Chandra Kroll for technical advice regarding flow cytometry.

\section{Supplemental Data}

Supplemental material for this article can be found at http://dx.doi.org/10.1016/j.ajpath.2016.06.007.

\section{References}

1. Muller LJ, Marfurt CF, Kruse F, Tervo TM: Corneal nerves: structure, contents and function. Exp Eye Res 2003, 76:521-542

2. Beuerman RW, Schimmelpfennig B: Sensory denervation of the rabbit cornea affects epithelial properties. Exp Neurol 1980, 69: 196-201

3. Bonini S, Rama P, Olzi D, Lambiase A: Neurotrophic keratitis. Eye (Lond) 2003, 17:989-995

4. Sacchetti M, Lambiase A: Diagnosis and management of neurotrophic keratitis. Clin Ophthalmol 2014, 8:571-579

5. Davis EA, Dohlman CH: Neurotrophic keratitis. Int Ophthalmol Clin 2001, 41:1-11

6. Linna TU, Vesaluoma MH, Perez-Santonja JJ, Petroll WM, Alio JL, Tervo TM: Effect of myopic LASIK on corneal sensitivity and morphology of subbasal nerves. Invest Ophthalmol Vis Sci 2000, 41: 393-397

7. Lockwood A, Hope-Ross M, Chell P: Neurotrophic keratopathy and diabetes mellitus. Eye (Lond) 2006, 20:837-839

8. Paton L: The trigeminal and its ocular lesions. Br J Ophthalmol 1926, 10:305-342

9. Cavanagh HD, Pihlaja D, Thoft RA, Dohlman CH: The pathogenesis and treatment of persistent epithelial defects. Trans Sect Ophthalmol Am Acad Ophthalmol Otolaryngol 1976, 81:754-769

10. Liesegang TJ: Corneal complications from herpes zoster ophthalmicus. Ophthalmology 1985, 92:316-324

11. Miller CS, Danaher RJ, Jacob RJ: Molecular aspects of herpes simplex virus I latency, reactivation, and recurrence. Crit Rev Oral Biol Med 1998, 9:541-562

12. Biswas PS, Rouse BT: Early events in HSV keratitis: setting the stage for a blinding disease. Microbes Infect 2005, 7:799-810

13. Carr DJ, Harle P, Gebhardt BM: The immune response to ocular herpes simplex virus type 1 infection. Exp Biol Med (Maywood) 2001, 226:353-366

14. Rowe AM, St Leger AJ, Jeon S, Dhaliwal DK, Knickelbein JE, Hendricks RL: Herpes keratitis. Prog Retin Eye Res 2013, 32:88-101

15. Stuart PM, Keadle TL: Recurrent herpetic stromal keratitis in mice: a model for studying human HSK. Clin Dev Immunol 2012, 2012: 728480

16. Stumpf TH, Shimeld C, Easty DL, Hill TJ: Cytokine production in a murine model of recurrent herpetic stromal keratitis. Invest Ophthalmol Vis Sci 2001, 42:372-378

17. Wickham S, Carr DJ: Molecular mimicry versus bystander activation: herpetic stromal keratitis. Autoimmunity 2004, 37:393-397

18. Wuest TR, Carr DJ: VEGF-A expression by HSV-1-infected cells drives corneal lymphangiogenesis. J Exp Med 2010, 207:101-115

19. Zheng M, Schwarz MA, Lee S, Kumaraguru U, Rouse BT: Control of stromal keratitis by inhibition of neovascularization. Am J Pathol 2001, 159:1021-1029

20. Gallar J, Tervo TM, Neira W, Holopainen JM, Lamberg ME, Minana F, Acosta MC, Belmonte C: Selective changes in human corneal sensation associated with herpes simplex virus keratitis. Invest Ophthalmol Vis Sci 2010, 51:4516-4522

21. Hamrah P, Cruzat A, Dastjerdi MH, Zheng L, Shahatit BM, Bayhan HA, Dana R, Pavan-Langston D: Corneal sensation and subbasal nerve alterations in patients with herpes simplex keratitis: an in vivo confocal microscopy study. Ophthalmology 2010, 117: $1930-1936$

22. Yun H, Rowe AM, Lathrop KL, Harvey SA, Hendricks RL: Reversible nerve damage and corneal pathology in murine herpes simplex stromal keratitis. J Virol 2014, 88:7870-7880

23. Chucair-Elliott AJ, Zheng M, Carr DJ: Degeneration and regeneration of corneal nerves in response to HSV-1 infection. Invest Ophthalmol Vis Sci 2015, 56:1097-1107

24. Mirabelli P, Peebo BB, Xeroudaki M, Koulikovska M, Lagali N: Early effects of dexamethasone and anti-VEGF therapy in an 
inflammatory corneal neovascularization model. Exp Eye Res 2014, $125: 118-127$

25. Pinto RD, Lira RP, Abe RY, Zacchia RS, Felix JP, Pereira AV, Arieta CE, de Castro RS, Bonon SH: Dexamethasone/povidone eye drops versus artificial tears for treatment of presumed viral conjunctivitis: a randomized clinical trial. Curr Eye Res 2015, 40:870-877

26. Weijtens O, Schoemaker RC, Romijn FP, Cohen AF, Lentjes EG, van Meurs JC: Intraocular penetration and systemic absorption after topical application of dexamethasone disodium phosphate. Ophthalmology 2002, 109:1887-1891

27. Austin BA, Halford WP, Williams BR, Carr DJ: Oligoadenylate synthetase/protein kinase R pathways and alphabeta TCR $+\mathrm{T}$ cells are required for adenovirus vector: IFN-gamma inhibition of herpes simplex virus-1 in cornea. J Immunol 2007, 178:5166-5172

28. Bryant-Hudson KM, Chucair-Elliott AJ, Conrady CD, Cohen A, Zheng M, Carr DJ: HSV-1 targets lymphatic vessels in the eye and draining lymph node of mice leading to edema in the absence of a functional type I interferon response. Am J Pathol 2013, 183:1233-1242

29. Royer DJ, Zheng M, Conrady CD, Carr DJ: Granulocytes in ocular HSV-1 infection: opposing roles of mast cells and neutrophils. Invest Ophthalmol Vis Sci 2015, 56:3763-3775

30. Chucair-Elliott AJ, Conrady C, Zheng M, Kroll CM, Lane TE, Carr DJ: Microglia-induced IL-6 protects against neuronal loss following HSV-1 infection of neural progenitor cells. Glia 2014, 62: $1418-1434$

31. Kaye S, Choudhary A: Herpes simplex keratitis. Prog Retin Eye Res 2006, 25:355-380

32. Carr DJ, Tomanek L: Herpes simplex virus and the chemokines that mediate the inflammation. Curr Top Microbiol Immunol 2006, 303: 47-65

33. Razavi S, Nazem G, Mardani M, Esfandiari E, Salehi H, Esfahani SH: Neurotrophic factors and their effects in the treatment of multiple sclerosis. Adv Biomed Res 2015, 4:53

34. Bennett JL, Zeiler SR, Jones KR: Patterned expression of BDNF and NT-3 in the retina and anterior segment of the developing mammalian eye. Invest Ophthalmol Vis Sci 1999, 40:2996-3005

35. Chaudhary S, Namavari A, Yco L, Chang JH, Sonawane S, Khanolkar V, Sarkar J, Jain S: Neurotrophins and nerve regenerationassociated genes are expressed in the cornea after lamellar flap surgery. Cornea 2012, 31:1460-1467

36. Chung ES, Lee KH, Kim M, Chang EJ, Chung TY, Kim EK, Lee HK: Expression of neurotrophic factors and their receptors in keratoconic cornea. Curr Eye Res 2013, 38:743-750

37. Busillo JM, Cidlowski JA: The five Rs of glucocorticoid action during inflammation: ready, reinforce, repress, resolve, and restore. Trends Endocrinol Metab 2013, 24:109-119

38. Erlandsson AC, Bladh LG, Stierna P, Yucel-Lindberg T, Hammarsten O, Modeer T, Harmenberg J, Wikstrom AC: Herpes simplex virus type 1 infection and glucocorticoid treatment regulate viral yield, glucocorticoid receptor and NF-kappaB levels. J Endocrinol 2002, 175:165-176

39. Brandt CR: The role of viral and host genes in corneal infection with herpes simplex virus type 1. Exp Eye Res 2005, 80:607-621

40. Bryant-Hudson KM, Gurung HR, Zheng M, Carr DJ: Tumor necrosis factor alpha and interleukin-6 facilitate corneal lymphangiogenesis in response to herpes simplex virus 1 infection. J Virol 2014, 88: $14451-14457$

41. Biswas PS, Banerjee K, Kinchington PR, Rouse BT: Involvement of IL-6 in the paracrine production of VEGF in ocular HSV-1 infection. Exp Eye Res 2006, 82:46-54

42. Pasieka TJ, Cilloniz C, Lu B, Teal TH, Proll SC, Katze MG, Leib DA: Host responses to wild-type and attenuated herpes simplex virus infection in the absence of Stat1. J Virol 2009, 83:2075-2087

43. Fenton RR, Molesworth-Kenyon S, Oakes JE, Lausch RN: Linkage of IL-6 with neutrophil chemoattractant expression in virus-induced ocular inflammation. Invest Ophthalmol Vis Sci 2002, 43:737-743

44. LeBlanc RA, Pesnicak L, Cabral ES, Godleski M, Straus SE: Lack of interleukin-6 (IL-6) enhances susceptibility to infection but does not alter latency or reactivation of herpes simplex virus type 1 in IL-6 knockout mice. J Virol 1999, 73:8145-8151

45. Hu K, Harris DL, Yamaguchi T, von Andrian UH, Hamrah P: A dual role for corneal dendritic cells in herpes simplex keratitis: local suppression of corneal damage and promotion of systemic viral dissemination. PLoS One 2015, 10:e137123

46. Cook SD, Paveloff MJ, Doucet JJ, Cottingham AJ, Sedarati F, Hill JM: Ocular herpes simplex virus reactivation in mice latently infected with latency-associated transcript mutants. Invest Ophthalmol Vis Sci 1991, 32:1558-1561

47. Halford WP, Gebhardt BM, Carr DJ: Mechanisms of herpes simplex virus type 1 reactivation. J Virol 1996, 70:5051-5060

48. Haruta Y, Rootman DS, Xie LX, Kiritoshi A, Hill JM: Recurrent HSV-1 corneal lesions in rabbits induced by cyclophosphamide and dexamethasone. Invest Ophthalmol Vis Sci 1989, 30:371-376

49. Shimeld C, Hill TJ, Blyth WA, Easty DL: Reactivation of latent infection and induction of recurrent herpetic eye disease in mice. J Gen Virol 1990, 71(Pt 2):397-404

50. Barron BA, Gee L, Hauck WW, Kurinij N, Dawson CR, Jones DB, Wilhelmus KR, Kaufman HE, Sugar J, Hyndiuk RA: Herpetic Eye Disease Study: a controlled trial of oral acyclovir for herpes simplex stromal keratitis. Ophthalmology 1994, 101:1871-1882

51. Nakao S, Hata Y, Miura M, Noda K, Kimura YN, Kawahara S, Kita T, Hisatomi T, Nakazawa T, Jin Y, Dana MR, Kuwano M, Ono M, Ishibashi T, Hafezi-Moghadam A: Dexamethasone inhibits interleukin-1beta-induced corneal neovascularization: role of nuclear factor-kappaB-activated stromal cells in inflammatory angiogenesis. Am J Pathol 2007, 171:1058-1065

52. Nakao S, Zandi S, Lara-Castillo N, Taher M, Ishibashi T, HafeziMoghadam A: Larger therapeutic window for steroid versus VEGF-A inhibitor in inflammatory angiogenesis: surprisingly similar impact on leukocyte infiltration. Invest Ophthalmol Vis Sci 2012, 53: 3296-3302

53. Yang YN, Bauer D, Wasmuth S, Steuhl KP, Heiligenhaus A: Matrix metalloproteinases (MMP-2 and 9) and tissue inhibitors of matrix metalloproteinases (TIMP-1 and 2) during the course of experimental necrotizing herpetic keratitis. Exp Eye Res 2003, 77:227-237

54. Schacke H, Docke WD, Asadullah K: Mechanisms involved in the side effects of glucocorticoids. Pharmacol Ther 2002, 96:23-43

55. Drucker C, Gewiese J, Malchow S, Scheller J, Rose-John S: Impact of interleukin-6 classic- and trans-signaling on liver damage and regeneration. J Autoimmun 2010, 34:29-37

56. Kamimura D, Ishihara K, Hirano T: IL-6 signal transduction and its physiological roles: the signal orchestration model. Rev Physiol Biochem Pharmacol 2003, 149:1-38

57. Ebihara N, Matsuda A, Nakamura S, Matsuda H, Murakami A: Role of the IL- 6 classic- and trans-signaling pathways in corneal sterile inflammation and wound healing. Invest Ophthalmol Vis Sci 2011, 52:8549-8557

58. Bluyssen HA, Rastmanesh MM, Tilburgs C, Jie K, Wesseling S, Goumans MJ, Boer P, Joles JA, Braam B: IFN gamma-dependent SOCS3 expression inhibits IL-6-induced STAT3 phosphorylation and differentially affects IL-6 mediated transcriptional responses in endothelial cells. Am J Physiol Cell Physiol 2010, 299:C354-C362

59. Braam B, Joles JA, Danishwar AH, Gaillard CA: Cardiorenal syndrome: current understanding and future perspectives. Nat Rev Nephrol 2014, 10:48-55

60. Pieraut S, Lucas O, Sangari S, Sar C, Boudes M, Bouffi C, Noel D, Scamps F: An autocrine neuronal interleukin-6 loop mediates chloride accumulation and NKCC1 phosphorylation in axotomized sensory neurons. J Neurosci 2011, 31:13516-13526 